\title{
Cognitive-Behavioral Family Treatment of Childhood Obsessive-Compulsive Disorder: A Controlled Trial
}

\author{
PAULA BARRETT, PH.D., LARA HEALY-FARRELL, M.C.P., AND JOHN S. MARCH, M.D.
}

\begin{abstract}
Objective: To evaluate the relative efficacy of (1) individual cognitive-behavioral family-based therapy (CBFT); (2) group CBFT; and (3) a waitlist control group in the treatment of childhood obsessive-compulsive disorder (OCD). Method: This study, conducted at a university clinic in Brisbane, Australia, involved 77 children and adolescents with OCD who were randomized to individual CBFT, group CBFT, or a 4- to 6-week waitlist control condition. Children were assessed before and after treatment and at 3 months and 6 months following the completion of treatment using diagnostic interviews, symptom severity interviews, and self-report measures. Parental distress, family functioning, sibling distress, and levels of accommodation to OCD demands were also assessed. Active treatment involved a manualized 14-week cognitivebehavioral protocol, with parental and sibling components. Results: By an evaluable patient analysis, statistically and clinically significant pretreatment-to-posttreatment change occurred in OCD diagnostic status and severity across both individual and group CBFT, with no significant differences in improvement ratings between these conditions. There were no significant changes across measures for the waitlist condition. Treatment gains were maintained up to 6 months of follow-up. Conclusions: Contrary to previous findings and expectations, group CBFT is as effective in reducing OCD symptoms for children and adolescents as individual treatment. Findings support the efficacy and durability of CBFT in treating childhood OCD. J. Am. Acad. Child Adolesc. Psychiatry, 2004;43(1):46-62. Key Words: child/adolescent obsessive-compulsive disorder, anxiety disorders, cognitive-behavioral therapy, family intervention.
\end{abstract}

Childhood obsessive-compulsive disorder (OCD) is a chronic and not uncommon psychological condition with lifetime prevalence estimates of $1 \%$ to $3 \%$ (Flament et al., 1989; Reinherz et al., 1993; Shaffer et al., 1996; Valleni-Basile et al., 1994; Zohar, 1999). This often debilitating childhood disorder is frequently as-

\footnotetext{
Accepted August 12, 2003.

Dr. Barrett is Senior Lecturer and Mrs. Healy-Farrell is a doctoral student and research fellow in the School of Applied Psychology, Griffith University, Australia. Dr. March is Associate Professor of Psychiatry in the Department of Psychiatry, Duke University, Durham, NC.

This study was supported by a National Health and Medical Research Council Grant. The authors acknowledge the assistance of Belinda Kelly in the preparation of this manuscript and the research assistance of Peta Hartmann, Rachelle O'Malley, Natalie Boulter, and Keri Pavia.

Readers interested in obtaining a copy of the FOCUS treatment manuals may contact the authors or Australian Academic Press at info@australianacademicpress. com.au; 32 Jeays Street, Bowen Hills 4006, Brisbane, Australia.

Reprint requests to Dr. Barrett, School of Applied Psychology, Griffith University, Mount Gravatt Campus, Brisbane, Queensland, 4111, Australia; e-mail: p.barrett@griffith.edu.au.

0890-8567/04/4301-0046@2003 by the American Academy of Child and Adolescent Psychiatry.

DOI: 10.1097/01.CHI.0000096367.43887.13
}

sociated with severe disruptions to academic performance, peer relationships, and family functioning (Adams et al., 1994; Cooper, 1996; Leonard et al., 1993; Toro et al., 1992).

Research investigating OCD in the context of the family has consistently found a bidirectional influence, insofar as families affect and are affected by OCD (March, 1995). Research suggests that children with OCD might come from families characterized by high levels of expressed emotion (i.e., high levels of criticism and overinvolvement; Hibbs et al., 1991), with low levels of emotional support, warmth, and closeness (Valleni-Basile et al., 1995). In addition, the families of children with OCD have been demonstrated to make less use of positive problem-solving, with parents also less likely to reward independence in their children (Barrett et al., 2002). The heightened distress experienced by children with OCD can be upsetting and disruptive to the family, which may prompt family members to become involved in their child's rituals and obsessive-compulsive demands. Studies have shown that family members often report involvement in and accommodation of obsessive-compulsive symptoms, 
with this resulting in increased marital discord and parental and sibling distress (Barrett et al., 2001; Cooper, 1996). Furthermore, families who become involved in OCD demands may inadvertently contribute to the coercive cycle maintaining the OCD symptoms, whereby the child with OCD may come to demand increasing levels of involvement and accommodation by family members. These findings highlight the importance of involving families in the assessment and treatment of childhood OCD.

The OCD Expert Consensus Guidelines (March et al., 1997a) for treating childhood OCD recommend cognitive-behavioral therapy (CBT) as the first-line treatment of choice for all prepubertal children who present with primary OCD, and for adolescents with mild or moderate OCD (i.e., score < 19 on Children's Yale-Brown Obsessive Compulsive Scale [CY-BOCS]) (Goodman et al., 1989a, 1989b). Although more recent trials of selective serotonin reuptake inhibitors (SSRIs) may alter future guidelines, at this stage treatment outcome results for CBT, including the long-term durability of its effects, seem to support these current guidelines. In the past 10 years there has been a surge in treatment outcome studies examining the efficacy of individual CBT for childhood and adolescent OCD, with significant improvements in obsessive-compulsive symptoms consistently shown (e.g., Franklin et al., 1998; March et al., 1994; Piacentini et al., 1994; Waters et al., 2001) While there is some variability across studies, with rates of improvement in CY-BOCS scores ranging from $25 \%$ to $67 \%$, indicating that some of these studies have done better than others, these outcomes are comparable to those found in treatment studies of adults with OCD (e.g., 62.8\% symptom reduction on Y-BOCS; Franklin et al., 2002). These treatment gains have demonstrated durability, with effects maintained up to 24 months after treatment (i.e., Wever and Rey, 1997). More recently, two studies (Fischer et al., 1998; Thienemann et al., 2001) have examined group CBT for adolescents with OCD in open trial designs; however, these preliminary studies found less dramatic improvements in obsessive-compulsive symptomatology. Table 1 outlines 10 open trial evaluations of CBT for childhood OCD involving parents. Only those using a standardized CBT treatment protocol incorporating a parental component are included; hence, trials primarily focused on psychopharmacological or exposure-only treatments have not been summarized here.
The present study is the first to evaluate the efficacy of a standardized cognitive-behavioral family treatment (CBFT) protocol for childhood OCD, with random assignment of participants to individual treatment, group treatment, or a waitlist control condition. Treatment outcome was measured across three broad domains: (1) child diagnostic status and symptom severity; (2) parental distress and family functioning; and (3) sibling distress and accommodation. Treatment durability was assessed at 3 months and 6 months after treatment and was measured across (1) child diagnostic status and symptom severity and (2) parental distress and family functioning.

It was hypothesized that there would be significant reductions across all areas after treatment and followup for children in the active treatment conditions versus the waitlist control condition. Based on previous findings (Fischer et al., 1998; Franklin et al., 1998; Thienemann et al., 2001; Waters et al., 2001), it was expected that reductions would be significantly higher in the individual treatment condition versus the group treatment condition.

\section{METHOD}

\section{SUBJECTS}

Subjects aged between 7 and 17 years were recruited through referrals from community mental health agencies, general practitioners, and child mental health specialists and via parental interest following media announcements. Children and adolescents were selected into this study on the basis of a DSM-IV (American Psychiatric Association, 1994) primary diagnosis of OCD. Exclusionary criteria included primary major depression or another primary anxiety disorder, primary externalizing disorder (including attention-deficit/hyperactivity disorder, oppositional defiant disorder, or conduct disorder), Tourette's syndrome, autistic spectrum disorder, schizophrenia, organic mental disorder, or mental retardation. Subjects receiving concurrent psychotherapy were also excluded from this study. Prior to inclusion in the study, subjects receiving concurrent psychopharmacological treatment were required to have remained on the same medication for at least a 3-month period, thereby allowing sufficient time for the medication to take effect, and were required to maintain this medication over the course of treatment. All participating children were required to have an IQ suspected to be within the normal range and at least one parent willing to attend weekly sessions.

The final cohort for this study consisted of 24 subjects in the individual CBFT condition, 29 subjects in the group CBFT condition (i.e., eight groups ranging in number of participants from 3 to 6 subjects per group), and 24 subjects in the waitlist control condition. Parents and siblings (aged 7-17 years), where possible, were also involved in assessments and treatment. Participant characteristics are presented in Table 2. In the individual CBFT condition, three subjects were stabilized on medications for OCD, all of whom continued with their medication throughout this study. In the group CBFT condition, there were nine subjects stabilized 
TABLE 1

Child Cognitive-Behavioral Treatment Studies Including Parental Involvement

\begin{tabular}{|c|c|c|c|c|c|}
\hline Study & Sample & Design & $\begin{array}{l}\text { Outcome } \\
\text { Measures }\end{array}$ & Results & $\begin{array}{l}\text { Strengths (+) and } \\
\text { Limitations (-) }\end{array}$ \\
\hline $\begin{array}{l}\text { March et al., } \\
1994\end{array}$ & $\begin{array}{l}N=15 \\
8-18 \text { yr } \\
10 \text { females } \\
5 \text { males }\end{array}$ & $\begin{array}{l}\text { Open trial } \mathrm{CBT} \pm \\
\text { drug or other } \\
\text { treatment } \\
\mathrm{M}=10 \text { sessions }\end{array}$ & $\begin{array}{l}\text { - Diagnostic } \\
\text { - Y-BOCS } \\
\text { - NIMH GOCS } \\
\text { - CGI scale }\end{array}$ & $\begin{array}{l}\text { - } 50 \% \text { mean reduction } \\
\text { Y-BOCS } \\
\text { - } 6 \text { patients asymptomatic } \\
\text { - Gains maintained } 18 \\
\text { months } \mathrm{f} / \mathrm{u} \\
\text { - Medication discontinu- } \\
\text { ation in } 6 \text { patients with } \\
\text { booster sessions }\end{array}$ & $\begin{aligned} &+ \text { Protocol driven } \\
&+ \text { Reliable, valid assessments } \\
&+ \text { Parental involvement } \\
& \text { - Varied treatment intensity } \\
& \text { (3-21 sessions) and } \\
& \text { content } \\
& \text { - F/u ranged from 3-21 } \\
& \text { months } \\
& \text { - No control condition } \\
&- \text { No structured diagnostic } \\
& \text { interviews }\end{aligned}$ \\
\hline $\begin{array}{l}\text { Piacentini } \\
\text { et al., } 1994\end{array}$ & $\begin{array}{l}N=3 \\
9-13 \text { yr } \\
3 \text { females }\end{array}$ & $\begin{array}{l}\text { Open trial CBT + } \\
\text { family only } \\
10 \text { sessions }\end{array}$ & $\begin{array}{l}\text { - K-SADS diagnosis } \\
\text { - CY-BOCS } \\
\text { - NIMH GOCS } \\
\text { - CGI scale }\end{array}$ & $\begin{array}{l}\text { - } 56 \% \text { mean reduction } \\
\text { CY-BOCS } \\
\text { - Gains maintained at 12- } \\
\text { month f/u } \\
\text { - } 51 \% \text { mean reduction in } \\
\text { NIMH GOCS }\end{array}$ & $\begin{array}{l}+ \text { Standardized } 10 \text {-wk } \\
\text { protocol } \\
+ \text { Reliable, valid assessments } \\
+ \text { Concurrent family } \\
\text { sessions } \\
\text { - F/u for only } 2 \text { patients } \\
\text { - Only CGI ratings at f/u } \\
\text { - Very small sample } \\
\text { - No control group }\end{array}$ \\
\hline $\begin{array}{l}\text { Knox et al., } \\
1996\end{array}$ & $\begin{array}{l}N=4 \\
8-13 \text { yr } \\
1 \text { females } \\
3 \text { males }\end{array}$ & $\begin{array}{l}\text { Open trial E/RP + } \\
\text { parent involve- } \\
\text { ment } \pm \text { drugs } \\
\text { Multiple } \\
\text { Baseline } \\
24 \text { sess. (3/wk) }\end{array}$ & $\begin{array}{l}\text { - ADIS-C/P } \\
\text { - Leyton Obsessional } \\
\text { Inventory - Child } \\
\text { - Monitoring }\end{array}$ & $\begin{array}{l}\text { - No clinical diagnosis of } \\
\text { OCD at post or 3-month } \\
\mathrm{f} / \mathrm{u} \\
\text { - } 1 \text { diagnosis of OCD at } \\
12 \text {-month f/u } \\
\text { - Leyton results } \\
\text { varied/inconclusive } \\
\text { - Improvements after } \\
\text { parental involvement in } \\
\text { E/RP }\end{array}$ & $\begin{array}{l}+ \text { Protocol driven } \\
+ \text { Standardized parental } \\
\text { involvement } \\
+ \text { Structured clinical } \\
\text { diagnostic interview } \\
\text { - Outcome assessment not } \\
\text { sufficient } \\
\text { - Design does not allow for } \\
\text { comparative effects of } \\
\text { E/RP with/without } \\
\text { parental involvement }\end{array}$ \\
\hline $\begin{array}{l}\text { Scahill et al., } \\
1996\end{array}$ & $\begin{array}{l}N=7 \\
10-15 \text { yr } \\
5 \text { males } \\
2 \text { females }\end{array}$ & $\begin{array}{l}\text { Open trial BT } \pm \\
\text { drug } \\
M=14 \text { sessions }\end{array}$ & $\begin{array}{l}\text { - Diagnostic } \\
\text { - CY-BOCS } \\
\text { - RCMAS } \\
\text { - CDI }\end{array}$ & $\begin{array}{l}\text { - } 61 \% \text { mean reduction } \\
\text { CY-BOCS } \\
\text { - Gains maintained } \\
\text { 3-month f/u } \\
\text { - } 6 \text { patients received 2-3 } \\
\text { booster sessions before } \\
\text { 6-month f/u } \\
\text { - } 3 \text { patients w/out BT } \\
\text { showed no change }\end{array}$ & $\begin{array}{l}\text { + Family component } \\
+ \text { Protocol driven } \\
\text { - No structured diagnostic } \\
\text { interviews } \\
\text { - Rater not blind to } \\
\text { intervention } \\
\text { - Nonrandom assignment } \\
\text { to control group }\end{array}$ \\
\hline $\begin{array}{l}\text { Wever \& Rey, } \\
1997\end{array}$ & $N=57$ & $\begin{array}{l}\text { Open trial CBT } \\
\text { alone, drug } \\
\text { alone, CBT } \\
\pm \text { drug } \\
2 \text { wkly sessions } \\
12 \text { daily sessions }\end{array}$ & $\begin{array}{l}\text { - CY-BOCS } \\
\text { - CBCL } \\
\text { - GFES }\end{array}$ & $\begin{array}{l}\text { CBT + drug } \\
\text { - } 60 \% \text { mean reduction in } \\
\text { CY-BOCS } \\
\text { - Gains maintained at } \mathrm{f} / \mathrm{u} \\
(\mathrm{M}=24 \text { months }) \\
\text { - } 68 \% \text { remission at post } \\
\text { - } 39 \% \text { weaned off drug } \\
\text { - } \text { Comorbid ODD }(21 \% \text { of } \\
\text { sample) demonstrated } \\
\text { poorer outcome }\end{array}$ & $\begin{array}{l}\text { + Large sample size } \\
+ \text { Family involvement } \\
+ \text { Protocol driven } \\
\text { - No control } \\
\text { group/random assignment } \\
\text { - No structural diagnostic } \\
\text { interviews } \\
\text { - F/u varied (8-60 months) } \\
\text { - Results for CBT + } \\
\text { medication group only } \\
\text { (other groups too small) }\end{array}$ \\
\hline
\end{tabular}




\section{TABLE 1}

Continued

\begin{tabular}{|c|c|c|c|c|c|}
\hline Study & Sample & Design & $\begin{array}{l}\text { Outcome } \\
\text { Measures }\end{array}$ & Results & $\begin{array}{l}\text { Strengths }(+) \text { and } \\
\text { Limitations }(-)\end{array}$ \\
\hline $\begin{array}{l}\text { Franklin et al., } \\
1998\end{array}$ & $\begin{array}{l}N=14 \\
10-17 \text { yr } \\
10 \text { males } \\
4 \text { females }\end{array}$ & $\begin{array}{l}\text { Open trial } \mathrm{CBT} \pm \\
\text { drug or other } \\
\text { treatment } \\
\mathrm{M}=16-18 \text { sessions }\end{array}$ & $\begin{array}{l}\text { - Diagnostic } \\
\text { - Y-BOCS } \\
\text { - OC symptom } \\
\text { ratings } \\
\text { - Hamilton }\end{array}$ & $\begin{array}{l}\text { - } 67 \% \text { mean reduction } \\
\text { Y-BOCS } \\
\text { - Gains maintained at f/u } \\
(\mathrm{M}=9 \text { months) } \\
\text { - } \mathrm{CBT} \text { alone as effective as } \\
\mathrm{CBT}+\text { drug } \\
\text { - No difference between } \\
\text { intensive vs. wkly sessions } \\
\text { - No difference in } \\
\text { depression }\end{array}$ & $\begin{aligned}+ & \text { Reliable, valid assessments } \\
+ & \text { Intensive vs. weekly } \\
& \text { delivery } \\
+ & \text { Parental involvement } \\
- & \text { Small sample for } \\
& \text { comparisons } \\
- & \text { No control condition } \\
- & \text { No structured diagnostic } \\
& \text { interviews } \\
- & \text { Nonrandom assignment } \\
& \text { to conditions } \\
& \text { (CBT/CBT+medication) }\end{aligned}$ \\
\hline $\begin{array}{l}\text { Fischer et al., } \\
1998\end{array}$ & $\begin{array}{l}N=15 \\
12-17 \text { yr } \\
9 \text { males } \\
6 \text { females }\end{array}$ & $\begin{array}{l}\text { Open trial group } \\
\text { CBT } \pm \text { drug } \\
7 \text { wkly sessions }\end{array}$ & $\begin{array}{l}\text { - CY-BOCS: } \\
\text { obsessions, } \\
\text { compulsions, total } \\
\text { score }\end{array}$ & $\begin{array}{l}\text { - } 32 \% \text { mean reduction in } \\
\text { CY-BOCS } \\
\text { - } 50 \% \text { mean reduction in } \\
\text { CY-BOCS at 6-month } \\
\mathrm{f} / \mathrm{u} \\
\text { - Significant reductions } \\
\text { maintained at 6-month } \\
\mathrm{f} / \mathrm{u} \text { for obsessions and } \\
\text { total score }\end{array}$ & $\begin{array}{l}+ \text { Examined efficacy of } \\
\text { group CBT } \\
+ \text { Protocol driven } \\
- \text { Insufficient assessment } \\
- \text { Only } 1 \text { family session } \\
- \text { No control group } \\
- \text { Assessment raters not } \\
\text { blind }\end{array}$ \\
\hline $\begin{array}{l}\text { Thienemann } \\
\text { et al., } 2001\end{array}$ & $\begin{array}{l}N=18 \\
13-17 \text { yr } \\
12 \text { males } \\
6 \text { females }\end{array}$ & $\begin{array}{l}\text { Open trial group } \\
\text { CBT } \pm \text { drug or } \\
\text { other treatment } \\
14 \text { wkly sessions }\end{array}$ & $\begin{array}{l}\text { - Diagnostic } \\
\text { - CY-BOCS } \\
\text { - CGI Scale } \\
\text { - CDI } \\
\text { - MASC } \\
\text { - CBCL } \\
\text { - PSI }\end{array}$ & $\begin{array}{l}\text { - } 25 \% \text { mean reduction in } \\
\text { CY-BOCS } \\
\text { - Reductions in MASC, } \\
\text { CDI, CBCL } \\
\text { - No change on PSI pre- to } \\
\text { post-treatment } \\
\text { - } 1 \text { patient did not } \\
\text { complete treatment }\end{array}$ & $\begin{array}{l}+ \text { Thorough assessment } \\
+ \text { Family involvement } \\
+ \text { Examined efficacy of } \\
\text { group CBT } \\
+ \text { Protocol driven } \\
- \text { No control group } \\
- \text { Concurrent other } \\
\text { treatments } \\
- \text { No f/u } \\
- \text { Assessments raters not } \\
\text { blind }\end{array}$ \\
\hline $\begin{array}{l}\text { Waters et al., } \\
2001\end{array}$ & $\begin{array}{l}N=7 \\
10-14 \text { yr } \\
4 \text { females } \\
3 \text { males }\end{array}$ & $\begin{array}{l}\text { Open trial CBT } \\
14 \text { wkly sessions }\end{array}$ & $\begin{array}{l}\text { - } \mathrm{ADIS}-\mathrm{C} / \mathrm{P} \\
\text { - } \mathrm{CY}-\mathrm{BOCS} \\
\text { - NIMH GOCS } \\
\text { - } \text { CGAS } \\
\text { - } \mathrm{MASC} \text { OC } \\
\text { - } \text { CDI } \\
\text { - FAD } \\
\text { - } \text { FAS }\end{array}$ & $\begin{array}{l}\text { - } 86 \% \text { success rate } \\
\text { (diagnosis-free) } \\
\text { - } 60 \% \text { mean reduction in } \\
\text { NIMH GOCS } \\
\text { - } 60 \% \text { mean reduction in } \\
\text { CY-BOCS } \\
\text { - Improvements maintained } \\
\text { at 3-month f/u } \\
\text { - Reductions in family } \\
\text { accommodation } \\
\text { - No change in family } \\
\text { functioning }\end{array}$ & $\begin{aligned} &+ \text { Protocol driven, } \\
& \text { family-based CBT } \\
&+ \text { Standardized treatment } \\
& \text { delivery } \\
&+ \text { Inclusion and exclusion } \\
& \text { criteria } \\
&+ \text { Reliable and valid } \\
& \text { assessments of child and } \\
& \text { family functioning } \\
&+ \text { Structured diagnostic } \\
& \text { interviews } \\
&+ \text { No concurrent treatment } \\
&- \text { No control group } \\
&- \text { Small sample }\end{aligned}$ \\
\hline
\end{tabular}

-Continued

on medications at pretreatment, with six subjects continuing with their medications throughout this study and two subjects being withdrawn from medication following treatment (one before the 3-month follow-up assessment and one prior to the 6-month assessment), while one subject had a reduced dose of medication prior to the 6-month follow-up assessment. Five subjects in the waitlist condition were stabilized on medication before waitlist.

The majority of the sample presented with three or more compulsions. Only one participant presented with compulsions only, with the majority of the sample presenting with two or more ob- 
TABLE 1

Continued

\begin{tabular}{|c|c|c|c|c|c|}
\hline Study & Sample & Design & $\begin{array}{l}\text { Outcome } \\
\text { Measures }\end{array}$ & Results & $\begin{array}{l}\text { Strengths }(+) \text { and } \\
\text { Limitations }(-)\end{array}$ \\
\hline $\begin{array}{c}\text { Piacentini et } \\
\text { al., } 2002\end{array}$ & $\begin{array}{l}N=42 \\
5-17 \mathrm{yr} \\
25 \text { females } \\
14 \text { males }\end{array}$ & $\begin{array}{l}\text { Open trial CBT } \pm \\
\text { drug } \\
M=12.5 \text { sessions }\end{array}$ & $\begin{array}{l}\text { - } \text { ADIS-C/P } \\
\text { - } \text { CY-BOCS } \\
\text { - NIMH GOCS } \\
\text { - CGI Scale } \\
\text { - COIS } \\
\text { - CDI } \\
\text { - } \text { MASC } \\
\text { - CBCL }\end{array}$ & $\begin{array}{l}\text { - } 45 \% \text { mean reduction in } \\
\text { NIMH GOCS } \\
\text { - No difference between } \\
\text { CBT alone or CBT + } \\
\text { drug } \\
\text { - } 79 \% \text { significantly } \\
\text { improved (i.e., CGI < 2) } \\
\text { - Severity of obsessions and } \\
\text { OCD-related academic } \\
\text { impairment associated } \\
\text { with poorer outcome }\end{array}$ & $\begin{array}{l}+ \text { Protocol driven } \\
+ \text { Family involvement } \\
+ \text { Large sample size } \\
+ \text { Reliable and valid } \\
\text { assessments } \\
\text { - Post raters not blind } \\
\text { - No control group } \\
\text { - } \text { Assessments at post did } \\
\text { not include all measures } \\
\text { - No f/u assessments }\end{array}$ \\
\hline
\end{tabular}

Note: ADIS-C/P = Anxiety Disorders Interview Schedule for Children-Child/Parent version (Silverman \& Albano, 1996); BT = behavioral therapy; CBCL = Child Behavior Checklist (Achenbach, 1991); GFES = Global Family Environment Scale; CBT = cognitive-behavioral therapy; CDI = Children's Depression Inventory (Kovacs, 1992); CGAS = Children's Global Assessment Scale (Schaffer et al., 1983); CGI = Clinical Global Impression ratings (NIMH, 1985); COIS = Child Obsessive-Compulsive Disorder Impact Scale (Piacentini and Jaffer, 1999); CY-BOCS = Children's Yale-Brown Obsessive Compulsive Scale (Goodman et al., 1989a,b); E/RP = exposure and response prevention; FAD = Family Assessment Device (Epstein et al., 1983); FAS = Family Accommodation Scale (Calvocoressi et al., 1995); $\mathrm{f} / \mathrm{u}$ = follow-up assessment; Hamilton = Hamilton Depression Scale (Hamilton, 1960); K-SADS = Schedule for Affective Disorders and Schizophrenia for School-Age Children (Ambrosini, 1988); MASC = Multidimensional Anxiety Scale for Children (March, 1997); MASC-OC = Multidimensional Anxiety Scale for Children, Obsessive-Compulsive screen (March, 1997); NIMH GOCS = National Institute of Mental Health Global Obsessive-Compulsive Scale (Insel et al., 1983); OCD = obsessive-compulsive disorder; ODD = oppositional defiant disorder; PSI = Parenting Stress Index (Abidin, 1995); RCMAS = Revised Children's Manifest Anxiety Scale (Reynolds and Richmond, 1978); Y-BOCS = Yale-Brown Obsessive Compulsive Scale (Goodman et al., 1989a,b).

sessions (95\% of sample). The most common compulsions included washing/cleaning rituals ( $57 \%$ of sample) and checking for reassurance $(57 \%$ of entire sample). The most common obsessions included fears of contamination/illness or disease ( $75 \%$ of sample) and aggressive obsessions, including fears of harm to self and others (62\% of sample).

In regard to comorbid diagnoses, $79 \%(n=61)$ of the entire sample presented with a secondary comorbid diagnosis, with $59 \%(n=46)$ of the entire sample presenting with more than one comorbid diagnosis. The most common comorbid diagnosis was generalized anxiety disorder $(n=46)$, followed by specific phobia $(n=27)$, then social phobia $(n=15)$, separation anxiety disorder $(n=13)$, dysthymic disorder $(n=4)$, and major depression $(n=2)$.

Using $\chi^{2}$ tests for categorical variables and one-way analyses of variance (ANOVAs) for continuous variables, comparisons of group differences were conducted on sociodemographic variables and pretreatment outcome measures, including National Institute of Mental Health Global Obsessive-Compulsive Scale ratings, CYBOCS total scores, and all child, parent, and sibling self-report measures. Comparisons across groups were also conducted for second and third comorbid diagnoses. There were no significant differences across groups on any of the sociodemographic or pretreatment variables.

TABLE 2

Participant Characteristics According to Treatment Condition

\begin{tabular}{lcccc}
\hline & $n$ & Mean Age, yr (SD) & No. of Siblings & Mean Age of Siblings, yr (SD) \\
\hline Individual CBFT & 24 & $10.75(2.54)$ & $13^{a}$ & $11.15(2.38)$ \\
$\quad$ Males & 12 & $11.50(2.47)$ & 7 & $12.36(2.92)$ \\
Females & 12 & $10.00(2.49)$ & 6 & $10^{a}$ \\
Group CBFT & 29 & $12.90(2.30)$ & 3 & 7 \\
$\quad$ Males & 13 & $12.08(2.43)$ & $7.00(3.79)$ \\
Females & 16 & $13.56(2.03)$ & $9^{a}$ & 2 \\
Waitlist & 24 & $11.75(3.05)$ & 7 & \\
Males & 13 & $11.54(2.60)$ & $12.00(3.63)$ & \\
Females & 11 & &
\end{tabular}

Note: CBFT = cognitive-behavioral family-based therapy.

${ }^{a}$ From different families. 


\section{MEASURES}

\section{Diagnostic and Symptom Severity Measures}

Anxiety Disorders Interview Schedule for Children-Parent Version. The Anxiety Disorders Interview Schedule for Children-Parent version (ADIS-P) (Silverman and Albano, 1996) was developed specifically to diagnose anxiety disorders in children and to differentiate these from other internalizing and externalizing disorders (Silverman and Eisen, 1992). Studies that have examined the reliability of the child and parent versions of the ADIS (ADIS-C/P) have shown good interrater and retest reliability, with results suggesting that this measure has the best psychometric properties for the diagnostic assessment of childhood anxiety disorders of the available measures (Piacentini and Bergman, 2000). The ADIS-C/P has demonstrated good sensitivity to treatment effects in both childhood anxiety research (Barrett et al., 1996; Kendall, 1994) and childhood OCD research (Knox et al., 1996; Waters et al., 2001). This interview was administered conjointly to the child's parents. At posttreatment and follow-up, diagnostic interviews were conducted by psychologists blind to the child's treatment condition and diagnostic status. Pretreatment and posttreatment interviews were conducted at the clinic, while interviews were administered over the phone at follow-up.

National Institute of Mental Health Global Obsessive-Compulsive Scale. The National Institute of Mental Health Global ObsessiveCompulsive Scale (NIMH GOCS) (Insel et al., 1983) is a clinicianrated device that consists of a single item measuring global diagnostic severity on a scale from 1 (minimal symptoms, within normal range) to 15 (very severe). The GOCS also provides a scale of global improvement, ranging from 1 (very much improved) to 7 (very much worse), with 4 indicating no change. The GOCS has demonstrated good to excellent retest reliability (Kim et al., 1992, 1993) and adequate to good convergent validity with the SCL-90 OC scale and the CY-BOCS (Taylor, 1998).

Children's Yale-Brown Obsessive Compulsive Scale. The CY-BOCS (Goodman et al., 1989a) is a widely used, clinician-rated, semistructured interview assessing the severity of OCD symptomatology. The CY-BOCS rates the severity of obsessions and compulsions across five scales (time occupied by symptoms, interference, distress, resistance, and degree of control over symptoms) and also provides a total severity score. Cutoffs generally used in evaluating the CYBOCS total score are mild (10-18; distress but not necessarily functional impairment), moderate (19-29; distress and functional impairment), and severe (30 or above; severe distress and serious impairment; March and Mulle, 1998). The CY-BOCS shows reasonable reliability and validity, with good to excellent interrater agreement and high internal consistency for the 10 items used in calculating the total score (Scahill et al., 1997).

\section{Self-Report Measures}

Multidimensional Anxiety Scale for Children. The Multidimensional Anxiety Scale for Children (MASC) (March, 1997) is a self-report measure that assesses anxiety symptoms in children across a number of scales, including physical symptoms, harm avoidance, social anxiety, and separation/panic. The MASC comprises 39 items assessing the frequency of anxiety symptoms/concerns, with items being scored 0 (not at all) to 3 (often), and provides a total anxiety score. Research has indicated that the MASC has good internal reliability and convergent validity (March, 1997; March et al., 1997b).

Children's Depression Inventory. The Children's Depression Inventory (CDI) (Kovacs, 1992) comprises 27 items assessing symp- toms of depression, scored 0 (absence of symptom), 1 (mild symptom), or 2 (definite symptom), with higher scores indicating increasing severity and a total score that ranges from 0 to 54 . The extensive use of the CDI in clinical and experimental research has provided ample data to support the reliability and validity of this measure (Kovacs, 1992).

McMaster Family Assessment Device. The McMaster Family Assessment Device (FAD) (Epstein et al., 1983) is a 53-item selfreport questionnaire that assesses family functioning across six dimensions (problem-solving, communication, roles, affective responsiveness, affective involvement, and behavior control), in addition to an overall summary score of general functioning. The FAD items are scored along a 4-point rating scale, ranging from strongly agree to strongly disagree; higher scores indicate less healthy family functioning. The general functioning score is obtained by summing the item scores for that scale and obtaining a mean score (total/12 items). Based on previous studies, a score below 2.0 is considered in the healthy range of functioning. Research has documented significant agreement between mothers and fathers on five of the seven subscales (Akister and Stevenson-Hinde, 1991), and a series of studies have demonstrated that the FAD has adequate test-retest reliability, moderate correlations with other self-report measures of family functioning, and significant differentiation between clinic-rated healthy and unhealthy families (Epstein et al., 1983; Miller et al., 1985). In the present study the general functioning subscale was used to measure overall family functioning at pretreatment, posttreatment, and follow-up assessments.

Depression Anxiety Stress Scale. The Depression Anxiety Stress Scale-21 (DASS-21) (Lovibond and Lovibond, 1995) is a short version of the original DASS self-report questionnaire containing 42 items assessing the severity/frequency of negative emotional symptoms. Respondents are required to rate the extent to which they experience each symptom on a 4-point Likert scale ranging from "did not apply to me at all" (0) to "applied to me very much" (3). The measure has three subscales (depression, anxiety, and stress), which are calculated by summing the scores of the relevant items. Clinical range, based on normative data, is defined as scores of 16.57 or above for stress, 12.75 or above for anxiety, and 9.26 or above for depression (Antony et al., 1998). Studies investigating the psychometric properties of the DASS have reported good validity and reliability.

Sibling Accommodation Scale. The Sibling Accommodation Scale (SAS) (Calvocoressi et al., 1995) was adapted from the Family Accommodation Scale (Calvocoressi et al., 1995) and uses 12 of the original items adjusted for use by siblings. This measure assesses the frequency and severity of sibling accommodation to OCD and provides a total by summing 8 of the 12 items, which are scored as 0 (never/no accommodation) to 4 (daily/extreme accommodation). There is an additional item that rates the sibling's distress associated with accommodation, and a further three items that assess the consequences of not participating in accommodation to their sibling's OCD behaviors. To date there are no studies evaluating the psychometric properties of this measure.

\section{TREATMENT PROTOCOL}

The treatment protocol ("Freedom From Obsessions and Compulsions Using Cognitive-Behavioral Strategies” [FOCUS]; Barrett et al., in preparation) used in the present study is a CBFT treatment protocol based on March and colleagues' individual CBT protocol ("How I Ran OCD Off My Land"; March et al., 1994; March and Mulle, 1998). Adapted from March's original work, the FOCUS program includes a structured parent and sibling protocol, differentiating this CBFT protocol from typical CBT, and allows for 
both individual and group treatment delivery. Waters et al. (2001), in their pilot study of this treatment protocol, presented preliminary findings for the efficacy of this protocol in treating children individually. Copies of the FOCUS treatment protocols are available from the first author upon request.

The treatment in the present study involved 14 weekly sessions and 2 booster sessions ( 1 month and 3 months after treatment), each running for approximately 1.5 hours. Each session included individual or group CBT with the child/group (50 minutes), parent skills training (30 minutes), and a family review of progress (10 minutes). There are broadly three different components of the FOCUS program: (1) psychoeducation, anxiety management, and cognitive therapy; (2) intensive exposure/response prevention; and (3) maintenance of gains, including resiliency building and relapse prevention. Component 1 is delivered across weeks 1 to 5, component 2 is delivered intensely across weeks 6 to 10 and then is monitored and reviewed throughout treatment, and component 3 is delivered in weeks 11 to 14 . The child sessions focused on psychoeducation, cognitive training, anxiety management training, developing stimulus hierarchies, graded exposure and response prevention, building buffer zones with support networks, and relapse prevention. Parent sessions were conducted by the same therapist following the child sessions and focused on psychoeducation, problem-solving skills, and strategies to reduce parental involvement in the child's symptoms, along with encouraging family support of home-based exposure and response prevention trials. At least one parent from each family was required to attend each parent session. In the majority of cases (75\% of the sample) mothers attended the parents group; in $25 \%$ of families, both parents attended. Because work or other commitments prevented both parents from attending sessions in the majority of cases, the therapists emphasized the importance of discussing session content with partners who were unable to attend. The program also emphasized that the coping strategies taught needed to be practiced as a family on a daily basis. Children could miss up to two sessions provided that missed sessions were caught up with the therapist before the next individual or group session. No family missed more than two sessions. The two booster sessions provided additional opportunities for children to gain assistance in generalizing the skills learned in previous sessions. Treatment satisfaction data were obtained from children and parents at the completion of each session. On average, sessions were rated to be fairly helpful/good to quite helpful/good. The complete treatment satisfaction data are available from the first author upon request. Table 3 presents a session-by-session outline of the FOCUS program.

\section{PROCEDURE}

Following referral, participants were screened for obsessivecompulsive symptomatology via a telephone interview with parents, and those children meeting the inclusion criteria were invited for an assessment at one of two university psychology clinics in the Brisbane and Gold Coast regions. On attending the clinic, the research aims were explained to all participants (parents and children) and written informed consent was gained from parents prior to assessments. Initial assessment interviews involved ADIS-P diagnostic interview with parents and the CY-BOCS symptom rating interview with children, conducted by clinically trained graduate students blind to the hypotheses of this study. Following the ADIS-P interviews, ratings of global severity were made by the interviewer using the NIMH GOCS scales. Parents were given self-report measures (including OCD child, sibling, and parent questionnaires) to return at a later appointment or by mail. This assessment procedure was repeated after treatment.
Children who met DSM-IV criteria for OCD based on initial interviews were randomly assigned to either an individual or group family-based CBT treatment condition, or a waitlist condition, ethically bound to a 4- to 6-week period based on the severity of distress typically associated with OCD. Subjects were assigned to intervention condition in a randomized block design that accounted for the child's age and timing of referral to this study. Whenever three or more children of the same age bracket (i.e., children $=7-12$ years; adolescents $=13-17$ years) were referred within in a 2 -week period, these children were entered into the group condition. This procedure ensured that participants were not waiting long intervals for sufficient numbers to run the group intervention. Children meeting exclusionary criteria for participation in this research, based on these initial interviews, were referred to appropriate community agencies as required.

Intermittent assessments were conducted during treatment at the beginning of session 6 (assessing progress over weeks 1-5) and at the beginning of session 11 (assessing gains over weeks 6-10) to provide an indication of clinical change over the 14-week treatment protocol. These assessments included self-report measures administered during the session and a rating of global severity and improvement by the clinician. In addition, self-report measures were sent home to families for parents and siblings to complete at pretreatment, posttreatment, and follow-up, which were returned either by mail or at the next appointment. Follow-up ADIS-P interviews, NIMH ratings, and CY-BOCS interviews were conducted over the phone and only included assessing for an OCD diagnosis. Research has shown that diagnostic interviews may be reliably conducted over the phone for screening and assessment (Gatz et al., 1995; Korner-Bitensky and Wood-Dauphinee, 1995; Sobin et al., 1993). Following the post-waitlist condition, children who still met criteria for OCD were offered the treatment protocol free of charge or were referred to another community agency for treatment.

To ensure research reliability of diagnoses at pre- and posttreatment assessment, all ADIS-P interviews were videotaped, and 25\% of these interviews were later reviewed and rated by a clinician blind to both the original interviewer's diagnoses and the treatment conditions. The overall $\kappa$ agreement for the presence of OCD between the two raters was 1.00 . For secondary diagnoses, the overall $\kappa$ again was 1.00 , and for third diagnoses there was an overall $\kappa$ of 0.86 . When disagreement occurred (only for the third diagnosis), the two clinicians reviewed the videotape together, discussed the case, and assigned a consensus diagnosis for the purposes of describing diagnostic data in this paper. In addition, all treatment sessions were videotaped, and treatment integrity checks were conducted to ensure adherence to the treatment manuals. The integrity checks showed $89 \%$ concordance between session and manual content. All treatment was conducted by graduate students, trained and supervised by the first author.

\section{RESULTS}

\section{Treatment Outcome}

According to parents' ADIS reports at posttreatment, 21 children ( $88 \%$ response rate) in the individual CBFT condition were without a diagnosis of OCD, compared to 22 children ( $76 \%$ response rate) in the group CBFT condition. All children in the waitlist condition continued to meet criteria for OCD at postwaitlist. A $\chi^{2}$ analysis was used to test differences in treatment response rates for individual and group con- 
TABLE 3

The FOCUS Program: Session Outline of a CBT Family Treatment Protocol for OCD

\begin{tabular}{|c|c|c|}
\hline Session No. & Child Session & Parent/Sibling Session \\
\hline 1. & $\begin{array}{l}\text { - Psychoeducation } \\
\text { - Developing a neuro } \\
\text { - Forming an expert } \\
\text { - Externalizing OCD }\end{array}$ & $\begin{array}{l}\text { behavioral framework } \\
\text { team }\end{array}$ \\
\hline 2. & $\begin{array}{l}\text { - Introducing tool kit } \\
\text { - Mapping OCD }\end{array}$ & - Psychoeducation continued \\
\hline 3. & $\begin{array}{l}\text { - More mapping } \\
\text { - Understanding anxiety and body clues } \\
\text { - Relaxation games }\end{array}$ & $\begin{array}{l}\text { - Physiology of anxiety } \\
\text { - Parental anxiety management }\end{array}$ \\
\hline 4. & $\begin{array}{l}\text { - Introduction to thoughts and feelings } \\
\text { - Self-talk and bossing back OCD }\end{array}$ & $\begin{array}{l}\text { - Psychoeducation of OCD } \\
\text { - How OCD impacts on siblings } \\
\text { - Anxiety management for siblings }\end{array}$ \\
\hline 5. & $\begin{array}{l}\text { - Thought traps of OCD } \\
\text { - Probability and responsibility } \\
\text { - Responses to OCD thoughts }\end{array}$ & $\begin{array}{l}\text { - Cognitive biases of OCD } \\
\text { - Rational responses to OCD } \\
\text { - Appropriate ways of responding to OCD demands }\end{array}$ \\
\hline 6. & $\begin{array}{l}\text { - Step plans } \\
\text { - Goal setting } \\
\text { - Introduce E/RP steps }\end{array}$ & $\begin{array}{l}\text { - Introduction to E/RP } \\
\text { - Developing a fear hierarchy }\end{array}$ \\
\hline 7. & $\begin{array}{l}\text { - Mapping OCD } \\
\text { - Review E/RP steps } \\
\text { - Rewards for partial successes }\end{array}$ & $\begin{array}{l}\text { - Managing behavioral difficulties } \\
\text { - More mapping OCD } \\
\text { - Fear hierarchies }\end{array}$ \\
\hline 8. & $\begin{array}{l}\text { - Mapping OCD } \\
\text { - Review E/RP steps } \\
\text { - Mapping parental and sibling involvement and } \\
\text { accommodation }\end{array}$ & $\begin{array}{l}\text { - Mapping parental and sibling } \\
\text { - Involvement and accommodation }\end{array}$ \\
\hline 9. & $\begin{array}{l}\text { - Family problem sol } \\
\text { - The 6-step plan } \\
\text { - Negotiating disenga }\end{array}$ & $\begin{array}{l}\text { ving strategies } \\
\text { agement of parental and sibling accommodation and involvement }\end{array}$ \\
\hline 10. & $\begin{array}{l}\text { - Mapping OCD } \\
\text { - Review E/RP steps } \\
\text { - Develop step plans for new activities to replace OCD }\end{array}$ & $\begin{array}{l}\text { - Who is your child without OCD? } \\
\text { - Activities to introduce into child's life to replace OCD }\end{array}$ \\
\hline 11. & $\begin{array}{l}\text { - Mapping OCD } \\
\text { - Review E/RP steps/new activities steps } \\
\text { - Mapping support networks }\end{array}$ & $\begin{array}{l}\text { - Overcoming obstacles in withdrawal of accommodation } \\
\text { - Support networks }\end{array}$ \\
\hline 12. & $\begin{array}{l}\text { - Mapping OCD } \\
\text { - Review E/RP steps/new activities steps } \\
\text { - OCD in disguise: doubt, slowness, avoidance }\end{array}$ & $\begin{array}{l}\text { - Reviewing sibling accommodation } \\
\text { - Identifying disguises of OCD and ways of managing them }\end{array}$ \\
\hline 13. & $\begin{array}{l}\text { - Review E/RP steps/new activities steps } \\
\text { - Mapping what OCD might look like in the future }\end{array}$ & - Planning futures without OCD \\
\hline 14. & $\begin{array}{l}\text { - Reviewing tool kit } \\
\text { - Reward ceremonies }\end{array}$ & \\
\hline 15. & $\begin{array}{l}\text { - Booster } 1 \text { (1 month) } \\
\text { - Review tool kit and prepare step plans }\end{array}$ & $\begin{array}{l}\text { - Parental support } \\
\text { - Sibling support }\end{array}$ \\
\hline 16. & $\begin{array}{l}\text { - Booster } 2 \text { (3 month) } \\
\text { - Review tool kit and prepare step plans }\end{array}$ & $\begin{array}{l}\text { - Parental support } \\
\text { - Sibling support }\end{array}$ \\
\hline
\end{tabular}

Note: Sessions 4, 8, 12, 15, and 16 are sibling sessions. Sibling session 1 occurred with siblings alone, session 2 with siblings and parents, and for session 3 siblings were with OCD child. This sometimes varied to suit the individual families or the group members. FOCUS = Freedom From Obsessions and Compulsions Using Cognitive-Behavioral Strategies; CBT = cognitive-behavioral treatment; OCD = obsessive-compulsive disorder; $\mathrm{E} / \mathrm{RP}=$ exposure and reponse prevention. 
ditions and revealed no significant difference in the frequency of children without a diagnosis of OCD across conditions. The difference between treatment response for active CBFT (including individual and group) versus waitlist was significant $\left(\chi^{2}[1, N=77]=\right.$ 40.87, $p<.001)$. In terms of comorbid diagnoses, Table 4 presents the frequency of comorbid diagnoses across groups at pre- and posttreatment. The $\chi^{2}$ tests revealed significant differences across the groups in the frequency of second diagnoses $\left(\chi^{2}[2, N=77]=11.30\right.$, $p<.005)$ and third diagnoses $\left(\chi^{2}[2, N=77]=17.90\right.$, $p<.001)$ at posttreatment. Follow-up $\chi^{2}$ tests revealed there were no significant differences in the frequency of comorbid diagnoses across individual and group CBFT conditions at posttreatment. Across the active CBFT groups, $42 \%(n=22)$ of the sample $(n=53)$ presented with a secondary comorbid diagnosis at posttreatment, compared with $83 \%(n=20)$ of the waitlist sample. Across the active CBFT groups, 21\% $(n=11)$ of the sample presented with more than one comorbid diagnosis at posttreatment, compared with $71 \%(n=17)$ of the waitlist group.
Table 5 presents means and standard deviations across all dependent variables, for each treatment condition, at pre- and posttreatment. Given the wide age range among participants ( $7-17$ years), initial analyses for treatment outcome were conducted with age as a between-subjects factor; however, these are not reported in this paper as there were no time $x$ age differences, or time $\times$ age $\times$ group differences across all dependent variables. Analyses reported for treatment outcome include 3 (group: individual CBFT, group CBFT, waitlist) $\times 2$ (time: pretreatment, posttreatment) repeated measures mixed factorial ANOVAs, with group between subjects, and time within subjects across all child, parent, and sibling measures. There were significant time $\times$ group interactions for NIMH GOCS ratings $\left(F_{2,74}=66.19, p<.001, \eta^{2}=0.64\right.$, power $=1.00)$ and CY-BOCS ratings $\left(F_{2,72}=31.42\right.$, $p<.001, \eta^{2}=0.47$, power $\left.=1.00\right)$. Tukey's HSD post hoc tests revealed no differences between the individual and group conditions; however, on both measures, individual and group conditions were significantly different from the waitlist condition. At posttreatment

TABLE 4

Frequency of Comorbid Diagnoses Across Groups at Pre- and Posttreatment/Waitlist

\begin{tabular}{|c|c|c|c|c|c|c|}
\hline & \multicolumn{6}{|c|}{ Pretreatment ADIS-P Comorbid Diagnoses } \\
\hline & \multicolumn{3}{|c|}{ 2nd Diagnosis ${ }^{a}$} & \multicolumn{3}{|c|}{ 3rd Diagnosis ${ }^{a}$} \\
\hline & Individual & Group & WL & Individual & Group & WL \\
\hline Frequency & 17 & 24 & 20 & 12 & 19 & 15 \\
\hline$\%$ & 71 & 83 & 83 & 50 & 66 & 63 \\
\hline SAD & 4 & 3 & 4 & 0 & 1 & 1 \\
\hline Social & 2 & 7 & 2 & 0 & 3 & 1 \\
\hline Specific & 3 & 4 & 3 & 5 & 4 & 8 \\
\hline GAD & 8 & 8 & 11 & 6 & 8 & 5 \\
\hline MD & 0 & 1 & 0 & 0 & 1 & 0 \\
\hline Dysthymia & 0 & 1 & 0 & 1 & 2 & 0 \\
\hline
\end{tabular}

\begin{tabular}{|c|c|c|c|c|c|c|}
\hline & \multicolumn{6}{|c|}{ Posttreatment ADIS-P Comorbid Diagnoses } \\
\hline & \multicolumn{3}{|c|}{ 2nd Diagnosis ${ }^{a}$} & \multicolumn{3}{|c|}{ 3rd Diagnosis ${ }^{a}$} \\
\hline & Individual & Group & WL & Individual & Group & WL \\
\hline Frequency & 9 & 13 & 20 & 5 & 6 & 17 \\
\hline$\%$ & 38 & 45 & 83 & 21 & 21 & 71 \\
\hline SAD & 0 & 3 & 4 & 1 & 0 & 2 \\
\hline Social & 1 & 1 & 3 & 1 & 0 & 2 \\
\hline Specific & 5 & 6 & 4 & 0 & 2 & 5 \\
\hline GAD & 3 & 1 & 9 & 3 & 3 & 7 \\
\hline MD & 0 & 0 & 0 & 0 & 0 & 0 \\
\hline Dysthymia & 0 & 2 & 0 & 0 & 1 & 1 \\
\hline
\end{tabular}

Note: ADIS-P = Anxiety Disorders Interview Schedule for Children-Parent version; WL = waitlist; SAD = separation anxiety disorder; Social $=$ social phobia Specific $=$ specific phobia GAD = generalized anxiety disorder; $\mathrm{MD}=$ major depression; Dysthymia $=$ dysthymic disorder .

a Second and third diagnosis status was decided based on severity of overall interference ratings. 
TABLE 5

Means and Standard Deviations Across Groups at Pre- and Posttreatment/Waitlist

\begin{tabular}{|c|c|c|c|c|c|c|}
\hline & \multicolumn{3}{|c|}{ Pretreatment/Waitlist } & \multicolumn{3}{|c|}{ Posttreatment/Waitlist } \\
\hline & Individual & Group & WL & Individual & Group & WL \\
\hline \multicolumn{7}{|c|}{ NIMH GOCS*** } \\
\hline Mean & 8.79 & 8.83 & 8.67 & 3.50 & 3.31 & $9.00^{* * *}$ \\
\hline $\mathrm{SD}$ & 1.62 & 1.37 & 1.81 & 2.30 & 2.16 & 2.00 \\
\hline$N$ & 24 & 29 & 24 & 24 & 29 & 24 \\
\hline \multicolumn{7}{|c|}{ CY-BOCS ${ }^{* * *}$} \\
\hline Mean & 23.64 & 21.38 & 22.95 & 8.36 & 8.28 & $24.04^{* * *}$ \\
\hline $\mathrm{SD}$ & 4.30 & 5.62 & 5.49 & 6.93 & 7.33 & 4.14 \\
\hline$N$ & 22 & 29 & 24 & 22 & 29 & 24 \\
\hline \multicolumn{7}{|l|}{ MASC $^{* *}$} \\
\hline Mean & 52.63 & 52.87 & 53.67 & 50.37 & 39.09 & 49.47 \\
\hline $\mathrm{SD}$ & 17.56 & 15.59 & 16.77 & 15.31 & 18.00 & 15.78 \\
\hline$N$ & 19 & 23 & 15 & 19 & 23 & 15 \\
\hline \multicolumn{7}{|l|}{$\mathrm{CDI}^{* *}$} \\
\hline Mean & 7.89 & 6.52 & 10.27 & 6.26 & 3.35 & 8.07 \\
\hline SD & 5.97 & 5.38 & 7.65 & 6.59 & 4.82 & 7.26 \\
\hline$N$ & 19 & 23 & 15 & 19 & 23 & 15 \\
\hline \multicolumn{7}{|c|}{ Mother FAD } \\
\hline Mean & 2.07 & 2.07 & 2.48 & 2.16 & 2.16 & 2.45 \\
\hline $\mathrm{SD}$ & 0.45 & 0.38 & 0.32 & 0.30 & 0.39 & 0.31 \\
\hline$N$ & 18 & 26 & 14 & 18 & 26 & 14 \\
\hline \multicolumn{7}{|c|}{ Father FAD } \\
\hline Mean & 2.01 & 2.13 & 2.38 & 2.12 & 2.13 & 2.33 \\
\hline $\mathrm{SD}$ & 0.45 & 0.38 & 0.11 & 0.37 & 0.45 & 0.23 \\
\hline$N$ & 9 & 13 & 10 & 9 & 13 & 10 \\
\hline \multicolumn{7}{|c|}{ Mother depression } \\
\hline Mean & 4.11 & 6.19 & 7.47 & 4.44 & 5.33 & 7.73 \\
\hline $\mathrm{SD}$ & 3.60 & 6.41 & 7.31 & 6.12 & 7.23 & 9.41 \\
\hline$N$ & 18 & 27 & 15 & 18 & 27 & 15 \\
\hline \multicolumn{7}{|c|}{ Mother anxiety } \\
\hline Mean & 5.44 & 3.81 & 4.13 & 2.83 & 4.30 & 7.73 \\
\hline $\mathrm{SD}$ & 7.94 & 6.05 & 5.88 & 4.20 & 7.10 & 9.88 \\
\hline$N$ & 18 & 27 & 15 & 18 & 27 & 15 \\
\hline \multicolumn{7}{|c|}{ Mother stress } \\
\hline Mean & 9.89 & 10.63 & 15.20 & 10.06 & 8.85 & 13.73 \\
\hline SD & 7.53 & 7.07 & 5.94 & 7.67 & 9.00 & 9.00 \\
\hline$N$ & 18 & 27 & 15 & 18 & 27 & 15 \\
\hline \multicolumn{7}{|c|}{ Father depression } \\
\hline Mean & 8.55 & 3.79 & 4.44 & 5.55 & 3.14 & 5.56 \\
\hline SD & 9.55 & 5.98 & 5.64 & 6.77 & 4.94 & 7.33 \\
\hline$N$ & 11 & 14 & 9 & 11 & 14 & 9 \\
\hline \multicolumn{7}{|c|}{ Father anxiety } \\
\hline Mean & 8.00 & 2.71 & 2.44 & 4.82 & 3.36 & 3.56 \\
\hline $\mathrm{SD}$ & 10.08 & 3.56 & 1.94 & 7.44 & 4.36 & 4.10 \\
\hline$N$ & 11 & 14 & 9 & 11 & 14 & 9 \\
\hline \multicolumn{7}{|c|}{ Father stress } \\
\hline Mean & 8.00 & 10.71 & 10.89 & 11.64 & 7.43 & 9.78 \\
\hline $\mathrm{SD}$ & 9.59 & 8.22 & 8.84 & 9.83 & 6.77 & 9.77 \\
\hline$N$ & 11 & 14 & 9 & 11 & 14 & 9 \\
\hline \multicolumn{7}{|c|}{ Sibling CDI*** } \\
\hline Mean & 6.67 & 4.10 & 9.11 & 1.92 & 3.20 & 7.00 \\
\hline $\mathrm{SD}$ & 5.05 & 4.31 & 5.30 & 2.11 & 3.94 & 4.92 \\
\hline$N$ & 12 & 10 & 9 & 12 & 10 & 9 \\
\hline
\end{tabular}


TABLE 5

Continued

\begin{tabular}{|c|c|c|c|c|c|c|}
\hline & \multicolumn{3}{|c|}{ Pretreatment/Waitlist } & \multicolumn{3}{|c|}{ Posttreatment/Waitlist } \\
\hline & Individual & Group & WL & Individual & Group & WL \\
\hline \multicolumn{7}{|c|}{ Sibling MASC } \\
\hline Mean & 41.23 & 36.90 & 54.78 & 34.08 & 30.50 & 57.56 \\
\hline $\mathrm{SD}$ & 11.97 & 9.92 & 14.20 & 11.30 & 10.16 & 15.66 \\
\hline$N$ & 13 & 10 & 9 & 13 & 10 & 9 \\
\hline \multicolumn{7}{|c|}{ Sibling accommodation** } \\
\hline Mean & 10.56 & 10.20 & 13.11 & 6.11 & 6.30 & 12.67 \\
\hline SD & 7.54 & 6.48 & 8.51 & 5.01 & 5.46 & 8.41 \\
\hline$N$ & 9 & 10 & 9 & 9 & 10 & 9 \\
\hline
\end{tabular}

Note: CDI = Children's Depression Inventory (Kovacs, 1992); CY-BOCS = Children's Yale-Brown Obsessive Compulsive Scale (Goodman et al., 1989a,b); FAD = Family Assessment Device (Epstein et al., 1983); MASC = Multidimensional Anxiety Scale for Children (March, 1997); NIMH GOCS = National Institute of Mental Health Global Obsessive-Compulsive Scale (Insel et al., 1983). Main effect for time is denoted by asterisks beside the measure name. Significant differences by treatment condition are denoted by asterisks in the final column. ${ }^{* *} p<.005 ;{ }^{* * *} p<.001$.

children in the active CBFT groups were rated significantly lower in severity than waitlist children. Inspection of the means reveals a mean reduction in CY-BOCS scores from pretreatment to posttreatment of $65 \%$ in the individual CBFT, compared to $61 \%$ in the group CBFT. For NIMH GOCS scores, there was a $60 \%$ decrease in mean ratings of severity for the individual CBFT, compared to $63 \%$ reduction in mean ratings for the group CBFT condition.

There were no significant time $\times$ group interactions for child CDI or MASC scores, but there were significant time main effects for MASC $\left(F_{1,54}=0.861, p<\right.$ $.005, \eta^{2}=0.14$, power $\left.=0.83\right)$ scores and CDI $\left(F_{1,54}=0.809, p<.005, \eta^{2}=0.19\right.$, power $\left.=0.94\right)$ scores. All groups showed reductions in MASC and CDI scores over time; however, inspection of the means reveals that group CBFT showed the highest reduction in MASC and CDI scores over time, and this difference did approach significance for MASC scores. In terms of clinical significance, at pretreatment/waitlist all groups fell within one standard deviation above the mean based on normative data; however, at posttreatment, while there was no change for individual CBFT or waitlist, the mean MASC score for group CBFT moved to fall within one standard deviation below the mean of the normative sample at posttreatment. The changes over time in CDI scores were less remarkable given that all groups were within normal range at pretreatment/waitlist.

On parent measures of FAD general functioning, there were no significant time, group, or time $\times$ group effects. At pretreatment, mothers and fathers across all groups scored above 2, and this did not change over time, indicating that families were within the unhealthy range of general functioning at pre- and posttreatment. On the parental DASS measure, there were no significant differences across time, group, or time $\times$ group on mothers' or fathers' ratings of depression, anxiety, or stress. In terms of clinical significance, all scores across groups fell below clinical range at pre- and posttreatment/waitlist for mothers and fathers.

On measures of sibling anxiety, depression, and accommodation to OCD demands, there were no significant time $\times$ group interactions, but there was a significant main effect of time for sibling CDI $\left(F_{1,28}=\right.$ 13.51, $p<.001, \eta^{2}=0.33$, power $\left.=0.94\right)$ and for sibling accommodation $\left(F_{1,25}=11.07, p<.005, \eta^{2}=\right.$ 0.31 , power $=0.89$ ). Across all groups there was a reduction in sibling levels of depression and accommodation to OCD demands over time. Self-reported levels of depression and anxiety were within normal range at pre- and posttreatment/waitlist, based on normative data. Inspection of the means for the sibling accommodation total score indicates that on average siblings reported mild to moderate levels of accommodation at pretreatment/waitlist, and negligible accommodation at posttreatment. Waitlist siblings remained to report mild to moderate accommodation at postwaitlist.

Analyses to test for clinical change across the 14 weeks of intervention and to evaluate the relative effects of treatment components included 2 (group: individual CBFT, group CBFT) $\times 4$ (time: pretreatment, week 6 , week 11, posttreatment) repeated measures mixed factorial ANOVAs, across child NIMH GOCS ratings and CDI and MASC scores. There were no 
significant time $\times$ group interactions, but there were significant time main effects for NIMH GOCS ratings $\left(F_{3,45}=89.01, p<.001, \eta^{2}=0.86\right.$, power $=$ $1.00)$, child CDI ratings $\left(F_{3,36}=4.70, p<.01, \eta^{2}=\right.$ 0.28 , power $=0.86)$, and child MASC ratings $\left(F_{3,36}=\right.$ $7.56, p<.001, \eta^{2}=0.39$, power $\left.=0.97\right)$. There was also a significant time main effect for NIMH global improvement ratings $\left(F_{2,46}=52.80, p<.001, \eta^{2}=\right.$ 0.70 , power $=1.00$ ) across week 6 to week 11 to posttreatment. Follow-up $t$ tests for NIMH GOCS ratings revealed significant reductions in severity from pretreatment to week $6\left(t_{50}=0.41, p<.005\right)$, week 6 to week $11\left(t_{(49}=0.78, p<.001\right)$, and week 11 to posttreatment $\left(t_{49}=0.70, p<.001\right)$ across active CBFT. Follow-up tests for child MASC ratings revealed significant reductions in anxiety from pretreatment to week $6\left(t_{43}=0.56, p<.001\right)$, week 6 to week 11 $\left(t_{46}=0.83, p<.001\right)$, and week 11 to posttreatment $\left(t_{48}=0.74, p<.001\right)$ across active CBFT. For child CDI scores, there were significant reductions in depression ratings from pretreatment to week $6\left(t_{42}=0.66, p\right.$ $<.001)$, week 6 to week $11\left(t_{47}=0.78, p<.001\right)$, and week 11 to posttreatment $\left(t_{49}=0.89, p<.001\right)$ across active CBFT. NIMH global improvement ratings showed significant progress in symptom reduction from week 6 to week $11\left(t_{49}=0.66, p<.001\right)$ and from week 11 to posttreatment $\left(t_{49}=0.62, p<.001\right)$ across active CBFT. Table 6 includes means and standard deviations across time for each group on NIMH GOCS, CDI, MASC, and NIMH global improvement ratings.

Analyses to examine the effects of combined CBFT and medication across time, in comparison to children who were not on medication, included 2 (group: active CBFT, including individual and group, without medication, and active CBFT + medication, including individual and group) $\times 2$ (time: pretreatment, posttreatment) repeated measures mixed factorial ANOVAs across child measures. There were no significant time $\times$ group interactions across any of these variables, indicating that children who were stabilized on medication at pretreatment did not differ in treatment gains from those who were not on medication. Analyses were not conducted on follow-up assessment data due to the variation in timing of medication withdrawal across $\mathrm{CBFT}+$ medication children over the follow-up period.

\section{Effects of Treatment at Follow-up}

Across analyses, variation in sample sizes was largely attributable to the failure of parents to return selfreport measures at each time point, in addition to

TABLE 6

Means and Standard Deviations for Individual and Group CBFT Across Pretreatment, Week 6, Week 11, and Posttreatment Assessments

\begin{tabular}{|c|c|c|c|c|c|c|c|c|}
\hline \multirow{2}{*}{$\begin{array}{l}\text { Measure (including time } \\
\text { main effects) }\end{array}$} & \multicolumn{4}{|c|}{ Individual CBFT } & \multicolumn{4}{|c|}{ Group CBFT } \\
\hline & Pre & Wk 6 & Wk 11 & Post & Pre & Wk 6 & Wk 11 & Post \\
\hline \multicolumn{9}{|l|}{ NIMH GOCS*** } \\
\hline Mean & 8.95 & 6.60 & 5.25 & 3.35 & 8.83 & 7.52 & 6.07 & 3.31 \\
\hline $\mathrm{SD}$ & 1.67 & 2.11 & 1.97 & 3.31 & 1.37 & 1.70 & 1.83 & 2.16 \\
\hline$N$ & 20 & 20 & 20 & 20 & 29 & 29 & 29 & 29 \\
\hline \multicolumn{9}{|l|}{$\mathrm{CDI}^{*}$} \\
\hline Mean & 8.28 & 7.22 & 7.17 & 6.61 & 6.77 & 7.73 & 5.32 & 3.45 \\
\hline SD & 5.90 & 6.62 & 7.65 & 6.60 & 5.37 & 6.85 & 4.75 & 4.91 \\
\hline$N$ & 18 & 18 & 18 & 18 & 22 & 22 & 22 & 22 \\
\hline \multicolumn{9}{|l|}{ MASC $^{* * *}$} \\
\hline Mean & 50.94 & 55.89 & 52.06 & 48.94 & 53.41 & 51.27 & 45.18 & 38.77 \\
\hline SD & 16.41 & 15.61 & 14.08 & 14.40 & 15.73 & 16.07 & 15.16 & 18.37 \\
\hline$N$ & 18 & 18 & 18 & 18 & 22 & 22 & 22 & 22 \\
\hline \multicolumn{9}{|l|}{ Improvement ${ }^{* * *}$} \\
\hline Mean & NA & 2.85 & 2.20 & 1.65 & NA & 3.10 & 2.07 & 1.48 \\
\hline SD & & 0.88 & 1.15 & 1.09 & & 0.62 & 0.88 & 0.69 \\
\hline$N$ & & 20 & 20 & 20 & & 29 & 29 & 29 \\
\hline
\end{tabular}

Note: CBFT = cognitive-behavioral family-based therapy; CDI = Children's Depression Inventory (Kovacs, 1992); MASC = Multidimensional Anxiety Scale for Children (March, 1997); NIMH GOCS = National Institute of Mental Health Global Obsessive-Compulsive Scale (Insel et al., 1983); Improvement = NIMH GOCS improvement ratings (i.e., not available at pretreatment; Insel et al., 1983); NA = not applicable. Main effect for time is denoted by asterisks beside the measure name. ${ }^{*} p<.01 ;{ }^{* * *} p<.001$. 
invalid responses as a result of missing items on selfreport measures. Questionnaires with missing data were considered invalid and were not included in analyses. At pretreatment, all children obtained diagnostic ratings and CY-BOCS ratings. At posttreatment, all children obtained diagnostic ratings, but two children did not complete CY-BOCS interviews within the 4-week period following posttreatment. Sixty-seven children $(87 \%)$ of the entire sample completed and returned valid self-report measures at pre- and posttreatment. At pretreatment 67 mothers $(87 \%$ of sample) and 47 fathers (61\% of sample) completed and returned valid self-report measures. At posttreatment, 66 mothers ( $86 \%$ of sample) and 41 fathers (53\% of sample) completed and returned valid self-report measures. Forty-six (87\%) of the original 53 children involved in active treatment were interviewed and included in the 3-month follow-up and 37 (70\%) were included in the 6-month follow-up. The completion and return rates of questionnaires at each follow-up point were approximately $70 \%$ for child self-report at 3 months, $57 \%$ for child at 6 months, $60 \%$ for mothers at 3 months, and $57 \%$ for mothers at 6 months. Fathers' completion rate for self-report measures at 3 and 6 months was $32 \%$ of the original 53 children participating.

To assess treatment durability, child and parent outcome measures were analyzed with 2 (group: individual CBFT, group CBFT) $\times 3$ (time: posttreatment, 3 month follow-up, 6-month follow-up) repeated measures mixed factorial ANOVAs. Follow-up analyses were also conducted using Tukey's post hoc tests. For each separate group of multiple ANOVAs, the Holm modified Bonferroni correction method (Jaccard and Guilamo-Ramos, 2002) was used to control for inflation of experiment-wise error. There were no significant time main effects or time $\times$ group interactions, indicating that the gains made at posttreatment were maintained at 6-month follow-up across NIMH GOCS ratings, NIMH global improvement ratings, CY-BOCS ratings, and CDI and MASC scores. There were also no significant time or time $\times$ group effects across parental FAD and DASS scores, indicating there were no changes over time on these measures.

In terms of diagnostic status at the 3-month followup, $82 \%$ of the individual CBFT participants available $(n=17)$ were OCD diagnosis free, compared to $76 \%$ of the group CBFT participants available $(n=29)$ for assessment at this time point. These response rates are comparable with posttreatment results. At the 6-month follow-up, $65 \%$ of the individual CBFT participants available $(n=14)$ were OCD diagnosis free, compared to $87 \%$ of the group CBFT participants available $(n=$ 23) for assessment at this time point. These lower results for individual CBFT condition in comparison to group CBFT at the 6-month follow-up are representative of the relatively smaller sample size actually contacted at this time point. The $\chi^{2}$ analyses revealed no significant differences across individual or group CBFT in diagnostic status at the 3-month or 6-month follow-up.

\section{DISCUSSION}

Both active CBFT conditions produced significant reductions in diagnostic status and severity ratings of obsessive-compulsive symptomatology in contrast to the waitlist control condition. Significant improvements occurred as early as week 6 in the treatment and continued across time to week 11, with improvements in child diagnostic status and obsessive-compulsive symptomatology maintained up to 6 months posttreatment. Measures of associated anxiety and depression in children declined for all groups over time, with no difference between groups from pre- to posttreatment, suggesting that any kind of intervention, including assessment and waitlist only, was associated with reductions in anxiety and depression for children and adolescents with OCD.

There were significant reductions across time for both the active CBFT and the waitlist condition in sibling levels of depression and accommodation to OCD demands. Although pretreatment sibling depression was not in the clinical range, a significant reduction in depression symptoms across all groups is noteworthy given that this was not directly targeted by the program, and may indicate that any kind of intervention for childhood OCD may alleviate distress or frustration for siblings. Further treatment outcome research, comparing the inclusion of a sibling component with no sibling component, may delineate whether decreased sibling depression and accommodation may be a consequence of symptom reduction in the child with OCD following CBT, or whether the inclusion of a sibling component in CBFT may facilitate such changes in family members themselves. Mild to moderate levels of sibling accommodation were reported on average across all groups at pretreatment/waitlist, which was similar to the accommodation levels re- 
ported by spouses and parents in Calvocoressi and colleagues' (1995) study of family accommodation to OCD in adults.

Similar to previous studies, these results demonstrate that CBT, including an active family component, is effective in reducing OCD in children and adolescents. In addition to adopting a randomized controlled design, this study is unique in finding comparable efficacy for individual and group CBFT delivery using a standardized treatment protocol. In terms of clinical significance, the results have replicated the high remission rate of Waters and colleagues' (2001) study of individual CBFT, while also finding no significant difference in remission rates for individual or group CBFT. These rates of remission were maintained at both the 3-month and 6-month follow-up. Interestingly, there were also reductions in comorbid diagnoses across pretreatment to posttreatment for children in active CBFT conditions, suggesting that secondary anxiety and depressive disorders are also reduced as a result of the effective treatment of OCD.

Analyses conducted with age group (children versus adolescents) as a between-subjects factor revealed no differential effects between the age groups and treatment delivery modalities (individual versus group CBFT) across time, suggesting that children and adolescents did not differ in their responsiveness to the individual or group treatment. Piacentini et al. (2002) also found no age differences in their open trial of individual CBT; however, this is the first study to investigate age effects in the efficacy of CBT for childhood OCD in the group format. These results suggest that the FOCUS program is developmentally sensitive and very flexible, insofar as it is equally effective across different age groups and across different modes of treatment delivery (individual and group). Furthermore, analyses investigating responsiveness to active CBFT for children stabilized on medication in comparison to children not on medication revealed no differences in treatment outcome between these groups, suggesting that CBT may be the treatment of choice for children and adolescents with mild to moderate OCD, as well as effectively treating any residual symptoms present in those receiving medication. The intermittent assessment of OCD severity, anxiety, depression, and global improvement at week 6 and week 11 revealed significant improvements for both individual and group CBFT across each of the three broad components (psychoeducation, exposure/response prevention, and relapse prevention), suggesting that each component might actively contribute to clinically significant change and reducing OCD symptomatology. Future research needs to further investigate the influence of each of these components by assessing their efficacy separately, or by counterbalancing their order within a controlled treatment design.

It was somewhat surprising that there were no differences across time in parental distress or family functioning for families in the active CBFT conditions. Inspection of the means and standard deviations for parental anxiety, depression, and stress indicates that while the mean scores were below clinical cutoff at both pre- and posttreatment, there was huge variability across individual scores, suggesting that families differed considerably in the amount of distress they experienced. Inspection of power analyses indicates insignificant power to detect time or time $\times$ group effects (power ranged from 0.05 to 0.20 ) on DASS scores for mothers and fathers. Furthermore, FAD scores were within the unhealthy range at both pre- and posttreatment across groups. Consistent with findings from observation studies (Barrett et al., 2002), these results suggest that families of OCD children might be more negative in both general functioning and interactions, and these characteristics might remain stable even throughout CBFT therapy for childhood OCD. Alternatively, the concurrent low levels of distress reported by parents, assessed by the DASS, may suggest that the FAD is overly sensitive, while the DASS may lack sensitivity. Nevertheless, the family involvement in this treatment was focused on managing the child's OCD and related problems and teaching parents and siblings strategies to manage their own distress within the context of the OCD. The family intervention did not target negative behavioral interactions or processes or parental or sibling clinical distress; hence, these factors might be influential in predicting outcome for parents and siblings involved in CBFT for childhood OCD. Continued refinement of the family component, including controlled studies evaluating the relative contribution of parent and sibling involvement, along with randomized controlled studies investigating the comparable effectiveness of CBT with and without the standardized family component, is needed to improve the effectiveness of the intervention for all family members.

To assess the generalizability of the present findings, the exportability of this manualized treatment protocol to other clinical settings and with more complex clients 
(with comorbid Tourette's syndrome, tic disorder, obsessional slowness) requires further research, including studies conducted across multiple sites. Further research is also necessary to evaluate the relative efficacy of CBT with and without medication in a controlled trial. In addition, while the results of this study are encouraging, further research is necessary to evaluate the durability of the treatment, for both individual and group conditions, over at least 1 to 3 years posttreatment.

\section{Limitations}

A number of limitations should be addressed before considering the general clinical implications of the findings. First, diagnostic interviews were conducted only with parents, therefore relying on subjective parental interpretation of child behaviors and cognitions. There could have been underestimations of child symptomatology, particularly when obsessions are not observable symptoms. It is generally recommended that multiple informants be used in assessing for childhood anxiety disorders, particularly OCD. Second, the reliability of the diagnoses was obtained by an independent observer reviewing videotapes of diagnostic interviews. Although this procedure has been commonly used in treatment trials for childhood anxiety studies, it may cause inflated reliability due to the restricted information available (the observer is unable to ask additional questions or query information provided by parents).

Considering that the majority of children in the waitlist condition either received the treatment protocol or were referred elsewhere for treatment, this study could not examine treatment versus no treatment effects at follow-up. Such analyses would provide information about the course of OCD and the persistence of the treatment effects over time. In addition, the restriction of the waitlist period due to ethical constraints may have inflated differences between the active conditions and the waitlist controls, where a longer waitlist period may have resulted in some control subjects making more substantial gains by the end of the period. Despite finding no differences between the outcomes following CBFT in children who received concurrent medication and those who received CBFT alone, only a small proportion of participants received concurrent pharmacotherapy throughout the course of this study, and type and dosage of medication were not controlled. Finally, due to the relatively low rate of completion of follow-up self-reports, the 3-month and 6-month follow-up data should be interpreted with caution.

\section{Clinical Implications}

The current study challenges previous findings that suggest that group CBT is less effective than individual CBT, and suggests that group therapy might be an attractive alternative for treating child and adolescent OCD. Therapists who ran group interventions described noticeable increases in child self-confidence as a result of the peer-learning experiences and the normalization process that is characteristic of group interventions. Moreover, the group CBFT condition resulted in the largest reductions in CDI and MASC scores from pre- to posttreatment, and while these reductions were not significantly higher than other groups, they do suggest that group CBFT might have added benefits than individual therapy. Given that OCD is often described as a secretive problem for children, group CBT seems to be an appealing treatment delivery option, particularly for adolescents who so often report feeling embarrassed, ashamed, and guilty about their OCD symptoms.

While the inclusion of a standardized family component does not appear to have been of huge benefit in the individual CBFT condition, feedback from parents and children involved in the group CBFT condition was overwhelmingly positive in terms of the level of social support and understanding that families experienced as a result of group therapy. Similarly, the overall rate of dropouts was low, with only three families withdrawing from the study, and these occurring only in the first 4 weeks of the study. Clinically, parents and siblings reported great satisfaction with the treatment and reported achieving substantial gains from their involvement in the program. Taken together with the comparatively high remission rate for the group condition in this study, these findings suggest that the standardized family component may be an essential component of the group treatment of childhood OCD. Furthermore, findings that families with a child who has OCD report unhealthy general family functioning and demonstrate negative behaviors during family interactions (Barrett et al., 2002) suggest that the effectiveness of family-based treatments for childhood OCD may be increased by addressing these negative family interaction processes more directly to improve the quality of family relationships and lessen the burden of OCD on the family. 
In summary, OCD in childhood is a complex psychological condition that causes significant problems for families and for clinicians attempting to treat the condition. The dissemination of a manualized treatment protocol such as FOCUS, backed with empirical support for its efficacy, will benefit both children and families living with OCD, and clinicians working with these families in fighting OCD. Based on evidence for the efficacy of this protocol in research settings, the FOCUS program will be refined to be published and disseminated for use by clinicians in the community, at which point its efficacy in community and private clinical settings may be evaluated.

\section{REFERENCES}

Abidin R (1995), Professional Manual for the Parenting Stress Index, 3rd ed. Odessa, FL: Psychological Assessment Resources

Achenbach T (1991), Manual for the Child Behavior Checklist/4-18 and 1991 Profile. Burlington: University of Vermont Department of Psychiatry

Adams G, Waas G, March J, Smith M (1994), Obsessive-compulsive disorder in children and adolescents: the role of the school psychologist in identification, assessment and treatment. Sch Psychol Q 9:274-294

Akister J, Stevenson-Hinde J (1991), Identifying families at risk: exploring the potential of the McMaster Family Assessment Device. J Fam Ther 13:411-421

Ambrosini P (Ed.) (1988), Schedule for Affective Disorders and Schizophrenia for School-Age Children (6-18 years) (K-SADS-IIIR). University of Pittsburgh (available at http://www.wpic.pitt.edu/ksads)

American Psychiatric Association (1994), Diagnostic and Statistical Manual of Mental Disorders, 4th edition (DSM-IV). Washington, DC: American Psychiatric Association

Antony M, Bielling P, Cox B, Enns M, Swinson R (1998), Psychometric properties of the 42-item and the 21-item versions of the Depression Anxiety Stress Scales in clinical groups and a community sample. Behav Res Ther 10:176-181

Barrett P, Dadds M, Rapee R (1996), Family treatment of childhood anxiety: a controlled trial. J Consult Clin Psychol 64:333-342

Barrett P, Rasmussen P, Healy L (2001), The effects of childhood obsessivecompulsive disorder on sibling relationships in late childhood and early adolescents: preliminary findings. Aust Educ Dev Psychol 17:82-102

Barrett P, Shortt A, Healy L (2002), Do parent and child behaviours differentiate families whose children have obsessive-compulsive disorder from other clinic and non-clinic children? J Child Psychol Psychiatry 43:597-607

Calvocoressi M, Lewis B, Harris M et al. (1995), Family accommodation in obsessive-compulsive disorder. Am J Psychiatry 152:441-443

Cooper M (1996), Obsessive compulsive disorder: effects on family members. Am J Orthopsychiatry 66:296-304

Epstein N, Baldwin L, Bishop D (1983), The McMaster Family Assessment Device. J Marital Fam Ther 9:171-180

Fischer D, Himle J, Hanna G (1998), Group behavioral therapy for adolescents with obsessive-compulsive disorder: preliminary outcomes. Res Soc Work 8:629-636

Flament M, Whitaker A, Rapoport J et al. (1989), An epidemiological study of obsessive-compulsive disorder in adolescence. In: Obsessive Compulsive Disorder in Children and Adolescents, Rapoport J, ed. Washington, DC: American Psychiatric Press, pp 253-267

Franklin M, Abramowitz J, Bux D, Zoellner L, Feeny N (2002), Cognitivebehavioral therapy with and without medication in the treatment of obsessive-compulsive disorder. Prof Psychol Res Pr 33:162-168

Franklin M, Kozak M, Cashman L, Coles M, Rheingold A, Foa E (1998), Cognitive-behavioral treatment of pediatric obsessive-compulsive disorder: an open clinical trial. J Am Acad Child Adolesc Psychiatry 37:412419
Gatz M, Reynolds C, Nikolic J, Lowe B, Karel M, Pedersen N (1995), An empirical test of telephone screening to identify potential dementia cases. Int Psychogeriatr 7:429-438

Goodman W, Price L, Rasmussen S et al. (1989a), The Yale-Brown Obsessive Compulsive Scale, I: development, use and reliability. Arch Gen Psychiatry 46:1006-1011

Goodman W, Price L, Rasmussen S et al. (1989b), The Yale-Brown Obsessive Compulsive Scale, II: validity. Arch Gen Psychiatry 46:10121016

Hamilton M (1960), A rating scale for depression. J Neurol Neurosurg Psychiatry 18:315-319

Hibbs E, Hamburger S, Lenane M et al. (1991), Determinants of expressed emotion in families of disturbed and normal children. J Child Psychol Psychiatry 32:757-770

Insel T, Hoover C, Murphy D (1983), Parents of patients with obsessivecompulsive disorder. Psychol Med 13:807-811

Jaccard J, Guilamo-Ramos V (2002), Analysis of variance frameworks in clinical child and adolescent psychology: advanced issues and recommendations. J Clin Child Adolesc Psychol 31:278-294

Kendall P (1994), Treating anxiety disorders in children: results of a randomised clinical trial. J Consult Clin Psychol 62:100-110

Kim S, Dysken M, Kuskowski N (1992), The Symptom Checklist-90 Obsessive-Compulsive subscale: a reliability and validity study. Psychiatry Res 41:37-44

Kim S, Dysken M, Kuskowski N, Hoover K (1993), The Yale-Brown Obsessive-Compulsive Scale and the NIMH Global ObsessiveCompulsive Scale (GOCS): a reliability and validity study. Int J Methods Psychiatry Res 3:37-44

Knox L, Albano A, Barlow D (1996), Parental involvement in the treatment of childhood obsessive-compulsive disorder: a multiple-baseline examination incorporating parents. Behav Ther 27:93-115

Korner-Bitensky N, Wood-Dauphinee S (1995), Barthel Index information elicited over the telephone: is it reliable? Am J Phys Med Rehabil 74:9-18

Kovacs M (1992), Children's Depression Inventory (CDI). Tonawanda, NY: Multi-Health Systems

Leonard H, Swedo S, Lenane M et al. (1993), A 2- to 7-year follow-up study of 54 obsessive-compulsive children and adolescents. Arch Gen Psychiatry 50:429-439

Lovibond P, Lovibond S (1995), The structure of negative emotional states: comparison of the depression anxiety stress scale (DASS) with the Beck depression and anxiety inventories. Behav Res Ther 33:335-343

March J (1995), Cognitive behavioral psychotherapy for children and adolescents with OCD: a review and recommendations for treatment. $J \mathrm{Am}$ Acad Child Adolesc Psychiatry 34:7-18

March J (1997), Manual for the Multidimensional Anxiety Scale for Children (MASC). North Tonawanda, NY: Multi-Health Systems

March J, Frances A, Kahn D et al. (1997a), Expert consensus guidelines: treatment of obsessive-compulsive disorder. J Clin Psychiatry 58:1

March J, Mulle K (1998), OCD in Children and Adolescents: A CognitiveBehavioral Treatment Manual. New York: Guilford

March J, Mulle K, Herbel B (1994), Behavioral psychotherapy for children and adolescents with obsessive-compulsive disorder: an open trial of a new protocol-driven treatment package. J Am Acad Child Adolesc Psychiatry 33:333-341

March J, Parker J, Sullivan K, Stallings P, Conners C (1997b), The Multidimensional Anxiety Scale for Children (MASC): factor structure, reliability, and validity. J Am Acad Child Adolesc Psychiatry 36:554565

Miller I, Epstein N, Bishop D, Keitner G (1985), The McMaster Family Assessment Device: reliability and validity. J Marital Fam Ther 11:345356

National Institute of Mental Health (1985), Special feature: rating scales and assessment instruments for use in pediatric psychopharmacological research. Psychopharmacol Bull 21

Piacentini J, Bergman R (2000), Obsessive-compulsive disorder in children. Psychiatr Clin North Am 23:519-533

Piacentini J, Gitow A, Jaffer M, Graae F, Whitaker A (1994), Outpatient behavioral treatment of child and adolescent obsessive-compulsive disorder. J Anxiety Disord 8:277-289

Piacentini J, Jacobs C, Bergman RL, Jacobs C, McCracken JT, Kretchman J (2002), Open trial of cognitive-behavior therapy for childhood obsessive-compulsive disorder. J Anxiety Disord 16:207-219 
Piacentini J, Jaffer M (1999), Preliminary Manual for the Child OCD Impact Scale (COIS). Los Angeles: University of California (available from Melody Keller, Childhood OCD \& Anxiety Program, 300 UCLA Medical Plaza, Suite 1315, Los Angeles, CA 90095-6967)

Reinherz H, Giaconia R, Lefkowitz E et al. (1993), Prevalence of psychiatric disorders in a community population of older adolescents. J Am Acad Child Adolesc Psychiatry 32:369

Reynolds C, Richmond B (1978), What I Think and Feel: a revised measure of children's manifest anxiety. J Abnorm Child Psychol 6:271-280

Scahill L, Riddle M, McSwiggan-Hardin M et al. (1997), The Children's Yale-Brown Obsessive Compulsive Scale: preliminary report of reliability and validity. J Am Acad Child Adolesc Psychiatry 36:844-853

Scahill L, Vitulano L, Brenner E, Lynch K, King R (1996), Behavioral therapy in children and adolescents with obsessive-compulsive disorder: a pilot study. J Child Adolesc Psychopharmacol 6:191-202

Shaffer D, Fisher P, Dulcan M et al. (1996), The NIMH Diagnostic Interview Schedule for Children (DISC-2): description, acceptability, prevalences and performances in the MECA Study. J Am Acad Child Adolesc Psychiatry 35:865

Shaffer D, Gould M, Brasic J et al. (1983), A children's global assessment scale (CGAS). Arch Gen Psychiatry 40:1228-1231

Silverman W, Albano A (1996), Anxiety Disorders Interview Schedule for DSM-IV: Parent Version. San Antonio, TX: Graywing

Silverman W, Eisen A (1992), Age differences in the reliability of parent and child reports of child anxious symptomatology using a structured interview. J Am Acad Child Adolesc Psychiatry 31:117-124
Sobin C, Weissman M, Goldstein R et al. (1993), Diagnostic interviewing for family studies: comparing telephone and face-to-face methods for the diagnosis of lifetime psychiatric disorders. Psychiatr Genet 3:227-233

Taylor S (1998), Assessment of obsessive-compulsive disorder. In: ObsessiveCompulsive Disorder: Theory, Research, and Treatment, Swinson R, Antony M, eds. New York: Guilford, pp 229-257

Thienemann M, Martin J, Cregger B, Thompson H, Dyer-Freidman J (2001), Manual driven group cognitive-behavioral therapy for adolescents with obsessive-compulsive disorder: a pilot study. J Am Acad Child Adolesc Psychiatry 40:1254-1260

Toro J, Cervera M, Osejo E, Salamero M (1992), Obsessive compulsive disorder in childhood and adolescence: a clinical study. J Child Psychol Psychiatry 33:1025-1037

Valleni-Basile L, Garrison C, Jackson K et al. (1994), Frequency of obsessive-compulsive disorder in a community sample of young adolescents. J Am Acad Child Adolesc Psychiatry 33:782

Valleni-Basile L, Garrison C, Jackson K et al. (1995), Family and psychosocial predictors of obsessive compulsive disorder in a community sample of young adolescents. J Child Fam Stud 4:193-206

Waters T, Barrett P, March J (2001), Cognitive-behavioral family treatment of childhood obsessive-compulsive disorder: an open clinical trial. Am J Psychother 55:372-387

Wever C, Rey J (1997), Juvenile obsessive-compulsive disorder. Aust NZJ Psychiatry 31:105-113

Zohar A (1999), The epidemiology of obsessive-compulsive disorder in children and adolescents. Child Adolesc Psychiatr Clin N Am 8:445-460 